\title{
A teoria da modernidade de Habermas e a questão do racionalismo ocidental: uma crítica à cegueira e à romantização do racionalismo
}

\author{
Habermas' theory of modernity and the question of western \\ rationalism: a critic to the blindness and romanticization of \\ rationalism
}

Leno Francisco Danner

lenofranciscodanner@gmail.com (Universidade Federal de Rondônia, Rondônia, Brasil)

\begin{abstract}
Resumo: Reconstruirei a compreensão habermasiana dos fundamentos do racionalismo ocidental e sua contraposição às visões míticas de mundo: o racionalismo possibilitaria, devido à sua capacidade de descentração e à sua separacão entre natureza, cultura e individualidade, a reflexivização da prática cotidiana e, com isso, a formação de uma consciência moral universalista, que garantiria a fundamentação formalista, universal das normas. A partir disso, defenderei que a posição habermasiana em relação ao racionalismo sofre de uma cegueira histórico-sociológica que, ao atribuir à cultura racionalista europeia superioridade em relação às visões de mundo mitológicas devido à capacidade de universalização daquela, por um lado reforça o sentido colonizador, missionário e messiânico do racionalismo europeu e, por outro, romanticiza o potencial universalista do racionalismo e sua episteme calcada na formalização dos valores. Meu argumento central consiste em que o único caminho que resta ao racionalismo é o voltar-se a uma crítica interna, recusando qualquer intento universalista.
\end{abstract}

Palavras-chave: Habermas; modernização; racionalismo; cultura europeia; culturas arcaicas.
Abstract: I will reconstruct the Habermasian comprehension of the foundations of Western rationalism and its contraposition to mythical worldviews: rationalism, based on its capability of decentration and its separation between nature, society and individuality, would enable the reflexivity of everyday practice and, therefore, the formation of a universalistic moral consciousness, that would ensure the formalist, universalist reasoning of the norms. From that, I will defend that the Habermasian position concerning rationalism suffers from a historical and sociological blindness that, attributing superiority to European rationalism over mythical worldviews because of rationalism's capability of universalization, reinforces, in one side, the settler, missionary and messianic sense of European rationalism, and, on the other side, romanticizes rationalism's universalist potential and its episteme based on the formalization of values. My central argument consist that the only way left to rationalism is to turn itself towards an internal critic, refusing any universalist intention.

Keywords: Habermas; modernization; rationalism; european culture; archaic cultures.

\section{Considerações iniciais}

A teoria da modernidade de Habermas possui um viés filosófico e um viés sociológico que o referido pensador procura integrar de maneira dinâmica. 0 viés 
filosófico consiste em apresentar um ponto de vista normativo que lhe permite manter a crítica às instituições e aos fenômenos sociais analisados, como sói acontecer geralmente com as posições filosóficas que não se concentram apenas na desconstrução dos saberes e das práticas próprios à ciência, à filosofia, à teologia e à cultura de matiz ocidental (por exemplo, Nietzsche, Foucault e Derrida, como acusa Habermas), mantendo, assim, um vínculo com a tradição filosófica ocidental. 0 viés sociológico, na medida em que afirma as instituições como estruturas objetivas configuradoras de processos de socialização e de subjetivação, lhe possibilita análises objetivas de fatos e de dinâmicas sociais, exatamente a partir daquele viés crítico fornecido pela filosofia. Por meio dessa interação entre filosofia e ciências sociais, assim, evitar-se-ia um puro positivismo sociológico, destituído de crítica (ainda segundo Habermas), mas também uma filosofia totalmente desligada da realidade da qual emerge e à qual quer apreender normativamente em conceitos - uma das intenções básicas da teoria social crítica desde o famoso escrito programático de Max Horkheimer, "Teoria tradicional e Teoria Crítica", enquanto dando o tom das pesquisas realizadas pela Escola de Frankfurt (cf. Habermas, 2004, pp.29-31).

No projeto teórico habermasiano, portanto, há uma afirmação da pretensão filosófica tradicional de fundamentação universalista dos valores epistemológicos e morais, da qual a ética do discurso é o principal substrato, mas combinada, conforme dito acima, com uma perspectiva interdisciplinar com as ciências sociais - Teoria do Agir Comunicativo, de 1981, é a obra magna que conjuga fundamentação filosófica e diagnósticos sociológicos do presente. No que tange à fundamentação filosófica, Habermas explicita que sua intenção é formular um conceito cético, porém não derrotista, de razão (cf. Habermas, 1990, p.07; 1991, p.32; 1993, p.104). Isto significa, por um lado, que ele assume as premissas do pensamento pós-metafísico, isto é, a historicidade, a contextualização e o pluralismo como pontos de partida da fundamentação filosófica, que impedem uma forma metafísico-teológica de fundamentação desses mesmos valores (cf. Habermas, 1990, pp.22-41; 2012a, pp.2021). Uma fundamentação metafísico-teológica, diga-se de passagem, implica em uma forte objetividade e universalidade desses mesmos valores, que não apenas seriam possíveis não obstante o escancarado pluralismo moral e religioso-cultural em sua historicidade e contextualização, senão que também constituir-se-iam nos juízes desses mesmos contextos particulares, conferindo à filosofia (ou à teologia, ou à ciência e à cultura de matiz euronorcêntrico) uma função claramente missionária e messiânica frente a eles.

Por outro lado, entretanto, Habermas não quer abandonar o projeto de fundamentação universalista dos valores epistemológicos e morais (por outras palavras, verdade e moralidade), porque acredita que a possibilidade de crítica social somente pode ser salva do ceticismo ou do conservadorismo se essa fundamentação 
universalista - se esse conceito não derrotista de razão - puder ser garantida filosoficamente. Sua grande contraposição àqueles pensadores que ele enquadrou como jovens conservadores (crítica pós-estruturalista da razão - Foucault e Derrida como exemplos, no entender de Habermas) (cf. Habermas, 2012a, pp.13-14; 1991, p.166; 2002a, pp.01-02, e p.07; 1997, p.33; Forst, 2010, p.08), ou seja, àqueles teóricos que realizam uma crítica radical ao racionalismo ocidental em sua pretensão de universalidade, reside exatamente neste motivo de elaboração de um conceito não derrotista de razão. Ou seja, Habermas crê que a destruição ou a recusa de tal pretensão universalista leva não apenas ao ceticismo epistemológico-moral, mas também, e principalmente, à impossibilidade de se realizar a crítica social, por meio de uma concepção objetiva de normatividade - o discurso filosófico da modernidade, como seu projeto basilar, consistiu na tentativa de oferecer essa fundamentação para um projeto epistemológico e ético-político de cunho universalista e Habermas não quer abandoná-lo, mas prossegui-lo reflexivamente (cf. Habermas, 2002b, pp.07$08)^{1}$.

Com isso, o racionalismo ocidental é o pressuposto filosófico-sociológico básico da teoria da modernidade elaborada por Habermas. Sua pretensão à universalidade é que permite a Habermas fundamentar uma concepção objetiva de normatividade que possa servir como substrato para sua teoria social crítica. Ao fazer isso, porém, Habermas é obrigado a assumir, ainda que com todos os cuidados por ele tomados, a pressuposição de superioridade desse mesmo racionalismo ocidental em relação às culturas pré-modernas ou arcaicas, exatamente por causa da pretensão de universalidade daquele, que estas não teriam. 0 racionalismo ocidental permitiria a formação de estruturas de consciência racionalizadas e formalistas, que, calcadas na separação entre natureza, cultura e individualidade, possibilitariam exatamente a fundamentação objetiva, formal, universal dos valores e das práticas, diferentemente das sociedades míticas, presas ao seu contexto de mundo e, assim, incapazes de crítica porque incapazes de formalização no que tange à fundamentação dos valores. Neste texto, quero estabelecer uma crítica à compreensão de Habermas em relação ao racionalismo e ao seu caráter fundamental em relação a um projeto crítico, teórico-prático, de emancipação, por estar calcado na fundamentação universalista dos valores epistemológico-morais.

\footnotetext{
1 Habermas, ainda a título de esclarecimento, também tem por objetivo enfrentar o neoconservadorismo político-cultural daqueles pensadores e grupos que, contrapostos ao individualismo dos estilos de vida e ao pluralismo religioso-cultural próprios da modernização ocidental, reafirmam tradições culturais fortes e nativas como solução à crescente perda de unidade social, ou que reafirmam apenas, como é o caso das posições neoliberais, o aspecto econômico da modernização ocidental, isto é, somente a modernização capitalista, recusando a modernização cultural (individualismo dos estilos de vida, pluralismo religioso-cultural, democracia, direitos, etc.). Sobre isso, pode-se conferir: Habermas, 2012a, pp.12-13; 1991, p.166; 2001, pp.137-138; 2002a, pp.06-08; Dubiel, 1993, p.02.
} 
Meu argumento principal está em que a interpretação habermasiana do racionalismo europeu moderno possui uma cegueira histórico-sociológica que idealiza e romanticiza esse mesmo racionalismo em sua pretensão de universalidade e em sua capacidade de descentração em relação à fundamentação dos valores, o que the permitiria exatamente alcançar um grau de formalização suficiente para gerar uma conduta de vida racional e uma construção universalista das normas morais, imbricadas - uma característica das estruturas de consciência modernas que as culturas primitivas, míticas, dificilmente teriam condições de gerar e de suprir. Esta cegueira histórico-sociológica, característica da compreensão habermasiana do racionalismo europeu moderno, idealiza esse mesmo racionalismo europeu no momento em que o coloca, por causa de sua pretensão de universalidade e de sua suposta alta reflexividade (dada a separação entre natureza, sociedade e indivíduo), na base de um projeto de normatividade que permite resgatar a crítica social e a possibilidade de um projeto emancipatório cosmopolita, que não estão apenas restritos ao seu contexto, senão que apontando para mais além. Além disso, há uma romantização do racionalismo europeu moderno no momento em que sua episteme calcada na formalização dos procedimentos de justificação é separada dos processos materiais que, tanto nas sociedades modernas quanto nos processos colonizatórios por estas levados a efeito em relação a outros povos e culturas, destruiu, com base nos valores universalistas e no modelo civilizacional (ciência, direito, razão, capitalismo, etc.) encampados pela Europa, as culturas primitivas que caíram sob seu jugo. Há, enfim, uma cegueira e uma romantização do racionalismo porque ele é visto como um processo em grande medida separado dos processos colonizatórios, missionários e messiânicos dinamizados desde a Europa contra as periferias, contra as culturas primitivas, o que o coloca como a utopia da salvação de um mundo turbulento, que precisa de esclarecimento.

Junto a isso, argumento que a crença na superioridade da episteme racionalista, que tem por base a formalização e a universalização das normas morais enquanto o fundamento para a legitimidade de qualquer regra e de qualquer prática contextual (concebendo, inclusive, os argumentos apenas fundados na dinâmica do contexto como não válidos porque não objetivos, incapazes de universalização), concebe tal processo de formalização e de universalização como uma tendência históricouniversal à qual todas as culturas e povos, se tiverem um nível de desenvolvimento similar à racionalização das imagens de mundo acontecida primeiramente na Europa, inevitavelmente alcançarão. Com isso, o modelo de racionalização europeu é alçado a uma etapa histórico-evolutiva não apenas superior, mas também a ser atingida por qualquer cultura que alcançar efetivo estágio de maturação interna. Isso também significa, em um âmbito mais filosófico, a ideia, clássica já na tradição filosófica ocidental, de que o universalismo epistemológico-moral não apenas é a forma de 
fundamentação por excelência, mas também a verdade do contextualismo: este somente encontra seu sentido naquele - o que significa, direta ou indiretamente, a deslegitimação dos saberes e das práticas das comunidades primitivas, arcaicas, que são percebidas, a partir da tradição filosófica ocidental, como incapazes de um pensamento formalista, universalista, como incapazes de abstraírem ou de se libertarem do contexto em que estão situadas. Para provar meus argumentos, dividirei o trabalho em dois momentos. No primeiro momento, reconstruirei a contraposição realizada por Habermas entre racionalismo ocidental e visão mítica de mundo, mostrado os motivos que levam Habermas a considerar a visão europeia moderna de mundo superior às imagens de mundo mitológicas. No segundo momento, procurarei construir minha crítica a esta cegueira histórico-sociológica e a esta romantização do racionalismo ocidental por Habermas. Nas considerações finais, argumentarei que, se há um futuro ao racionalismo ocidental, este consiste em voltar-se contra si próprio, no sentido de uma radical crítica interna à sua tendência colonizadora, missionária e messiânica (por meio da superação de sua cegueira histórico-sociológica e da romantização de suas capacidades e vinculações), cessando toda pretensão universalista que ele apresenta.

\section{0 racionalismo ocidental na teoria da modernidade de Habermas}

O ponto de partida da teoria da modernidade de Habermas consiste na afirmação de que, na consciência de mundo moderna, existem estruturas de consciência racionalizadas que permitem uma vida reflexiva e baseada em razões com validade intersubjetiva. Trata-se, com isso, de uma compreensão de mundo que apresenta uma pretensão à universalidade no que tange à fundamentação dos valores, diferentemente das culturas arcaicas. Diz Habermas:

À medida que procuramos aclarar o conceito de racionalidade com base no uso da expressão "racional", tivemos de nos apoiar sobre uma pré-compreensão que se encontra ancorada em posicionamentos modernos de consciência. Até o momento, partimos do pressuposto ingênuo de que, na compreensão moderna de mundo, se expressam certas estruturas da consciência que pertencem a um mundo da vida racionalizado e por princípio possibilitam uma compreensão racional da vida. Implicitamente, relacionamos à nossa compreensão de mundo ocidental uma pretensão de universalidade (Habermas, 2012a, p.94; o grifo é meu).

Ora, para entender o significado e as características dessa pretensão à universalidade própria à cultura europeia moderna, Habermas compara-a com a compreensão de mundo mítica. Ele acredita, em relação a isso, que os mitos, próprios das sociedades arcaicas, proporcionam o maior contraste em relação à compreensão de mundo dominante nas sociedades modernas, na medida em que "estão muito longe de nos possibilitar orientações racionais para a ação, no sentido que as entendemos" 
(Habermas, 2012a, p.94). Os mitos, por outras palavras, não fornecem condições para uma condução racional da vida. Note-se que Habermas não está querendo significar, com isso, que a diferença entre as sociedades míticas e as sociedades modernas resida no plano das capacidades mentais ou cognitivas mais desenvolvidas dos membros destas sociedades modernas em relação aos membros daquelas sociedades arcaicas, ou seja, em princípio, ele pressupõe que membros adultos das sociedades tribais primitivas são capazes de adquirir as mesmas operações formais que fazem parte da consciência dos indivíduos de sociedades modernas. Porém, ainda segundo Habermas, as competências cognitivo-morais de nível mais elevado surgem com pouca frequência e de modo mais seletivo nas sociedades arcaicas, em virtude de algumas características internas específicas às imagens de mundo (e não às capacidades mentais dos indivíduos) próprias dessas mesmas sociedades arcaicas.

Ora, quais são as características dos mitos? Primeiramente, o pensamento selvagem apresenta uma força totalizadora (cf. Habermas, 2012a, p.97), no sentido de que o mito interliga todos os aspectos da existência, assim como possibilita uma explicação completa de todos os fenômenos. Nenhum aspecto da vida cotidiana está fora da explicação mitológica do mundo e nem separado do todo de que faz parte. Em segundo lugar, o mito apresenta uma posição concretista que, por não conseguir alcançar padrões formais de compreensão e de ação, atribui existência objetiva a tudo o que existe, baseando as tomadas de postura e as interpretações cotidianas em relações de semelhança e de diferença (cf. idem, p.99). Por fim, em terceiro lugar, as imagens de mundo míticas apresentam traços mágico-animistas (cf. idem, p.100), no sentido de que a natureza possui traços antropomórficos e a sociedade traços naturalizados, mesclando-se e fundindo-se, inclusive, os mundos natural, social e sobrenatural, que ficam em completa interdependência. Nesse sentido, os poderes anônimos dessa totalidade, de ordem natural ou sobrenatural, subsumem a sociedade, a cultura e as vidas individuais, que ficam reificadas e completamente dominadas por poderes anônimos, que somente são acessados pela magia.

Desse modo, continua Habermas, percebido a partir do pensamento ilustrado próprio da cultura europeia moderna, o pensamento selvagem apresenta uma dupla ilusão: uma ilusão sobre si mesmo, na medida em que, por conceber as imagens de mundo por ele criadas como independentes a ele, é assimilado e completamente submetido a elas, deixando os indivíduos de sua cultura indefesos e impotentes tanto em relação à sua visão de mundo quanto em relação ao contexto que os subsume; e uma ilusão sobre o mundo, pois o percebe como possuindo seres imaginários análogos ao ser humano, o que faz com que os fenômenos sejam dinamizados por meio da ação de poderes míticos, de modo que apenas a intervenção mágica no mundo pode garantir estabilidade a esses mesmos fenômenos determinados de modo sobrenatural (cf. Habermas, 2012a, p.101). 
Aqui chegados, podemos nos perguntar, seguindo a reflexão de Habermas: por que as imagens míticas de mundo não permitem uma orientação racional da ação? Isso se deve a três aspectos fundamentais do mito, ligados às suas características acima explicitadas. Em primeiro lugar, o mito não permite uma diferenciação conceitual básica entre coisas e pessoas, entre agir instrumental e agir normativo. Em segundo lugar, o mito não permite a separação entre natureza e cultura, o que confere naturalidade à organização social e aos papéis sociais e práticas culturais cotidianas. Como consequência disso, sociedades organizadas a partir de uma visão mitológica apresentam valores e práticas dogmáticos, não-racionais e, por isso, privados de uma atitude crítico-reflexiva, bem como negadores dessa mesma postura críticoreflexiva. Em terceiro lugar, os membros dessas sociedades arcaicas vincularam férrea e fortemente a sua própria identidade ao saber coletivo miticamente estabelecido e aos seus rituais. Ou seja, como não há separação entre natureza, cultura e personalidade, os indivíduos não conseguem construir uma identidade autônoma em relação ao contexto que os subsume - por outras palavras, não há individualidade em sentido estrito nas sociedades míticas, já que não há uma concepção formal do eu que thes permita separar aquilo que são enquanto indivíduos da totalidade social e da natureza (cf. Habermas, 2012a, pp.102-108).

Logo, não há transformação social, mobilidade e dinamicidade em termos de crítica e de reformulação das tradições, senão que estas são superpostas aos indivíduos, que são subsumidos a elas, que se entendem como possuindo sentido somente dentro delas. Em consequência, as imagens míticas de mundo são fechadas sob dois pontos de vista: apresentam uma diferenciação deficiente entre os mundos objetivo ou natural, social e subjetivo; e possuem um déficit de reflexividade. Diz Habermas:

Imagens de mundo míticas não são entendidas pelos envolvidos como sistemas interpretativos atrelados a uma tradição cultural, constituídos por nexos internos de sentido, simbolicamente referidos à realidade, vinculados a pretensões de validade e, portanto, passíveis de crítica e aptos à revisão (Habermas, 2012a, p.109).

Por outras palavras, os indivíduos das comunidades arcaicas não entendem sua visão de mundo como uma construção intersubjetiva, como sua construção, mas sim como sendo prévias a eles próprios e enfeixando-os. Aliado a isso, a subsunção da individualidade na dinâmica objetiva da sociedade e da natureza, imbricadas, implica em que aconteça a falta de reflexividade de que fala Habermas enquanto definidora da dinâmica interna dessas sociedades míticas. Os indivíduos, assim, não submetem sua sociedade, sua cultura e suas tradições à crítica e nem à reformulação.

A visão de mundo moderna, europeia, por sua parte, apresenta uma pretensão de racionalidade ou é simplesmente uma cultura particular influenciada pela ciência? A cultura moderna, com isso, é universal, tem uma pretensão à universalidade, 
ou é uma visão de mundo particularista tal qual a visão mítica de mundo das sociedades arcaicas? Aqui chegados, é interessante que Habermas, em Teoria do Agir Comunicativo, assuma que o critério fundamental para a avaliação da estruturação e da superioridade de uma visão de mundo específica consiste no ponto de vista cognitivo, na capacidade de uma concepção de mundo em formular um conceito de verdade que possa assumir o aspecto universalista, que seja formal o suficiente para abstrair do particularismo de seu contexto de origem, sustentando pretensões objetivas, universais de validade. Verdade, nesse caso, seria o critério avaliativo do grau de desenvolvimento de uma cultura devido ao fato de que esta conseguiria sustentar universalmente e garantir um assentimento geral de sua própria normatividade diante das pretensões de validade particularistas de outras culturas ou posições morais. Interessantemente, a verdade, concebida em um sentido universalista, é colocada como a base da maturação de uma visão de mundo e mesmo da comparação entre visões de mundo. Isso ocorre porque, como defende Habermas, não obstante sempre ser objeto de uma concepção de mundo que é totalizante e particularista (já que possui um contexto), a verdade não pode ser entendida em sentido particularista, mas sim universalista, já que precisa ser sustentada por razões que recebam o assentimento geral (particularmente quando se trata de sociedades modernas, mas mesmo mais além, no entender de Habermas). "Seja qual for o sistema linguístico que escolhamos, sempre partimos intuitivamente do pressuposto de que a verdade seja uma pretensão universal de validade" (Habermas, 2012a, p.119). Presas ao contexto de origem e determinadas por ele, os valores não alcançam universalidade e, assim, não possuem potencial crítico nem podem ser criticados a partir do contexto, já que é este que os define de maneira férrea.

Verdade, aqui, tem ligação direta com sua capacidade de formalização, com sua capacidade de abstração dos contextos particulares e, assim, com a possiblidade de ela receber assentimento universal com base em razões, independentemente de ter sido formulada nesta ou naquela língua. Perceba-se que o aspecto da formalização ganha papel chave no que tange à maturação das concepções de mundo e, como consequência, à sua capacidade de gerar ações racionais - racionais porque formais, universais, que abstraem dos contextos particulares e nem se remetem a eles em última instância para sua fundamentação (cf. Habermas, 2012a, pp.119121). Racionalidade significa potencial de formalização, de universalização, ou seja, capacidade de assumir uma abordagem epistemológico-moral que abstraia dos contextos de uso particulares, garantindo uma concordância universal - essa seria, como venho afirmando, a condição básica para a possibilidade de crítica social, na medida em que somente aqui teríamos, no entender de Habermas, uma concepção objetiva de normatividade social que permitiria o julgamento crítico das diferentes dimensões da sociedade, das instituições, dos processos de socialização 
e de subjetivação e até mesmo das diferentes culturas entre si (direitos humanos poderiam ser enquadrados neste último ponto).

Assim, quanto mais fechada e centrada uma imagem do mundo é em relação a si mesma e aos indivíduos que a compõem, mais totalizante e reificadora ela é, menos chances de transformação crítica e de justificação universalista ela possibilita. Por outro lado, quanto mais descentrada é uma imagem de mundo, menos ela consegue velar de antemão o dogmatismo e o autoritarismo, abrindo espaço para uma crítica generalizada por parte dos indivíduos e dos grupos sociais, o que leva a que esses mesmos indivíduos e grupos tenham de construir, por meio da interação, suas práticas e justificar cooperativamente seus valores. Nas imagens de mundo fechadas, que são incapazes de formalização ou descentração, como é o caso das imagens míticas de mundo, a autoridade e a dinâmica sociocultural possuem uma justificação que é prévia aos indivíduos e aos grupos, que os subsume de maneira tão forte que impede a crítica a elas por parte desses indivíduos e grupos. As imagens de mundo míticas, por não serem formais ou descentradas, como consequência, impedem a crítica, a responsabilidade individual e os processos de fundamentação dialógico-cooperativa acerca dos valores. Diz Habermas:

$\mathrm{Na}$ medida em que se interpreta o mundo da vida de um grupo social por meio de uma imagem de mundo mítica, priva-se o participante individual tanto do ônus da interpretação quanto da chance de aproximar-se de um comum acordo criticável (Habermas, 2012a, p.140).

Imagens de mundo míticas falham em um triplo aspecto: (a) impedem o surgimento da individualidade enquanto separada da cultura da qual esta mesma subjetividade emerge; (b) impedem, por causa da subsunção dessas subjetividades à concepção de mundo da qual emergem, o entendimento de que a cultura é uma criação humana, sujeita à correção; o que leva (c) a que a crítica e a atividade social de fundamentação dos valores sejam invalidadas. Aqui chegados, podemos nos perguntar com Habermas: quais qualidades formais são necessárias às tradições culturais para que estas possam viabilizar orientações racionais para a ação? Habermas elenca quatro aspectos que possibilitam às tradições culturais gerarem orientações racionais para a ação: (a) elas precisam diferenciar os mundos objetivo ou natural, social e subjetivo, por meio de concepções formais específicas a cada um, fomentando pretensões de validade específicas a cada aspecto (verdade proposicional, correção normativa, verdade subjetiva) e gerando, com isso, posicionamentos individuais e grupais sobre tais mundos - ou seja, tal diferenciação leva à necessidade de razões ou de fundamentações que permitam uma justificação e um julgamento objetivo a cada caso (ou cognitivo, ou normativo, ou expressivo, etc.), por parte dos indivíduos e grupos; (b) as tradições culturais precisam ser autorreflexivas, precisam estimular reflexividade por parte de seus membros, gerando, como consequência, processos 
de aprendizagem - com isso, elas deixariam de ser dogmáticas, abrindo-se a uma revisão crítica dos próprios membros, pois que as tradições herdadas podem ser postas em questão; (c) as tradições culturais precisam levar à institucionalização de argumentações especializadas - ciência, moral, direito, música, arte, literatura, etc., como exemplos dados por Habermas - que passam a assumir a tarefa de revisão crítica permanente dessas mesmas tradições culturais, em cada área específica; por fim, (d) as tradições culturais precisam levar à separação entre sistema e mundo da vida, isto é, à institucionalização das práticas e das normas, por um lado, e à espontaneidade da esfera vital, por outro, que ainda assim manteriam imbricação e dinamicidade - as instituições, enquanto feixes de regras, orientariam os processos de socialização e de individuação, ao passo que a espontaneidade dos mundos da vida permitiria o ajuizamento crítico das instituições e, assim, seu aperfeiçoamento ao longo do tempo, por parte dos indivíduos e dos grupos (cf. Habermas, 2012a, pp.140-141).

Como enfatiza Habermas, a capacidade de formalização ou de universalização das normas, isto é, a possibilidade de sua justificação e de sua fundamentação discursiva em âmbito universal, é o aspecto mais importante para a formação de uma concepção de mundo moderna, autorreflexiva, para uma vida racionalizada, que não fica presa aos contextos particulares de uso, senão que consegue realizar fundamentações e ajuizamentos objetivos, formalistas (jurídica e moralmente) sobre os valores e as práticas. Com isso, pode-se definir a racionalidade ou a racionalização como possuindo as seguintes características: consolidação do individualismo dos estilos de vida ou noção forte de subjetividade, separada, independente da natureza e da sociedade; sujeitos orientam-se pelo entendimento; há pretensões de validade universais; a cultura e a sociedade, assim como as instituições em geral, dependem de uma legitimação intersubjetiva, de modo que a cultura não é independente aos indivíduos e aos grupos e nem os subsume; há, em consequência, uma compreensão de mundo descentralizada, calcada no universalismo moral. Diz Habermas:

Atribuímos racionalidade a todos os sujeitos que estejam orientados pelo entendimento e, com isso, por pretensões de validade universais, fazendo subjazer a suas realizações interpretativas um sistema referencial de mundos intersubjetivamente válido ou, digamos, uma compreensão de mundo descentralizada (Habermas, 2012a, p.249).

Uma concepção de mundo racional ou racionalizada aspira à universalidade, isto é, à discussão e à fundamentação universalista, formalista, descentrada, de seus valores e práticas, não ficando presa nem subsumida ao contexto; posturas racionais de vida são posturas reflexivas, no sentido de possibilidade de argumentação, justificação e ação com base em valores universalistas, formalistas, descentrados, gerando ações autônomas, autorreflexivas. Em nenhum dos dois casos o contexto vital subsume ou determina de maneira completa a fundamentação dos valores, 
senão que é transcendido, no que tange à tarefa de fundamentação. É óbvio, como sugere Habermas, que sempre vivemos em contextos e que as concepções de mundo influenciam nossas ações (mesmo nós, os modernos), mas a sua ideia de uma fundamentação universalista em termos cognitivos e morais aponta para o fato de que pretensões epistemológicas e morais somente podem adquirir validade se forem justificadas universalmente, se não ficarem restringidas ao particularismo dos contextos de uso - a cultura europeia moderna, por meio de sua racionalização, de sua descentração, de sua formalização, teria alcançado esse patamar. Antes de abordar especificamente este ponto, gostaria de retomar uma afirmação de Habermas, acima comentada en passant, de que a descentração da compreensão de mundo seria o aspecto mais fundamental de uma compreensão de mundo, com vistas a extrair dali duas consequências importantes.

A primeira delas, consoante Habermas, consiste em que "a descentração da compreensão de mundo e a racionalização do mundo da vida são condições necessárias para uma sociedade emancipada" (Habermas, 2012a, p.146. Cf., ainda: Honneth, 2003, pp.271-275; Forst, 2010, p.14). Habermas liga, aqui, emancipação ou autorreflexão com (a) capacidade de formalização da fundamentação das normas e das práticas (isto significa descentração) por parte de uma cultura; e (b) com a capacidade de racionalização da ação por parte dos indivíduos e dos grupos dessa cultura, que lhes permitiria argumentarem, justificarem e, em última instância, fundamentarem seus valores de modo universal, formalista, abstraindo-os dos contextos particulares de uso, inclusive, se necessário, reformulando as práticas do próprio contexto de uso. Isso seria sinônimo de esclarecimento, porque a crítica e a transformação social, bem como a maturação individual, teriam seu fundamento nessa possibilidade de discussão e de fundamentação universalistas, descentradas em relação ao contexto de uso, que ofereceriam tanto um paradigma normativo objetivo (posto que é universal) quanto a capacidade de formalização, isto é, de pôrse no lugar dos outros, de avaliar imparcialmente diferentes valores e práticas. Isso as concepções míticas ou presas ao contexto vital do qual emergem não conseguiriam fazer. Uma postura axiológica e cognitiva universalista, por conseguinte, é o que caracteriza as sociedades modernas (cf. Habermas, 2012a, p.148, e p.168).

A segunda delas pode ser percebida na utilização, por Habermas, do conceito piagetiano de descentração (adotar os pontos de vista uns dos outros, assumir a perspectiva dos outros, superando o egocentrismo e o etnocentrismo) como chave para o entendimento dos processos de racionalização das imagens de mundo, mormente das imagens de mundo modernas, isto é, com este conceito é possível captar processos sociais de progressiva formalização dos valores e das práticas, que gradativamente são separados pelos indivíduos de sua forte vinculação a um contexto específico. Com isso, a fundamentação cognitivo-moral desses valores não tem mais 
por fundamento esse mesmo contexto, e sim um procedimento de universalização que depende da interação entre os indivíduos e grupos, buscando concordância e validade universais. Ou seja, como quer Habermas, o processo de descentração do mundo, que leva à progressiva racionalização ou formalização das formas culturais, instaura a centralidade da racionalidade comunicativa enquanto base para a formulação e reformulação das tradições socioculturais, enquanto o médium para a fundamentação dos valores e das práticas das sociedades modernas, que são sociedades pós-tradicionais. Sociedades modernas são sociedades pós-tradicionais porque seus valores e suas práticas, suas instituições, seus processos de socialização e de subjetivação são fundamentados e construídos com base na fundamentação intersubjetiva (ou tendo-a como pressuposto), com base em processos formais de comunicação e de entendimento que aspiram à universalidade, à ampla participação e aceitação de seus membros. Eles não ficam mais presos a uma férrea determinação das tradições culturais, senão que, uma vez negada a fundamentação com base na autoridade das tradições, são construídos reflexiva e cooperativamente - possuindo, assim, um caráter universal. Enfim, a racionalização do mundo consolida a razão comunicativa como o médium da evolução social. E a razão comunicativa, de acordo com Habermas, "refere a compreensão de mundo descentrada à possibilidade de solvência discursiva de pretensões de validade criticáveis" (Habermas, 2012a, p.142; 2004, pp.08-20; 2002b, pp.19-22; Honneth, 2007b, pp.61-65; Forst, 2010, pp.210211). Ora, a modernidade encontra seu sentido no universalismo epistemológicomoral, possibilitado por meio da racionalidade comunicativa.

Então, o que significa modernização, segundo Habermas? Significa o desenvolvimento de um processo correlato de institucionalização do Estado burocrático, da economia capitalista e do direito positivo e de formação de estruturas de consciência pós-tradicionais, originados a partir de um processo de racionalização das imagens de mundo (cf. Habermas, 2012a, p.355, pp.384-385, pp.448-454; 2012b, pp.315-316, pp.323-325; 2003a, p.11). No primeiro caso, temos a institucionalização de sistemas de ação instrumentalistas (embora o direito, como quer Habermas, também mantenha ligação com a normatividade do mundo da vida); no segundo caso, temos a gênese e a consolidação do universalismo moral enquanto base das estruturas de consciência modernas, pós-tradicionais. Quero me deter, para o que me interessa neste artigo, no segundo aspecto. A racionalização do mundo da vida significa, como quer Habermas, a separação entre cultura, sociedade e personalidade. Essa característica da racionalização é importante, porque tal separação torna reflexivas as estruturas sociais, a cultura, os próprios indivíduos modernos, de modo que a fundamentação dos valores e das práticas já não depende de - nem se baseia em - nada que esteja para além desses mesmos indivíduos e grupos, senão que se funda nos acordos comunicativos baseados em razões e em pretensões universais 
de validade (cf. Habermas, 2012a, p.305; 2012b, p.263; 2003b, p.38, e p.94; Honneth, 2003, p.258; Forst, 2010, p.196). Isso significa, ainda segundo Habermas, que as sociedades modernas possuem um nível de aprendizagem e de maturação que nenhuma outra organização sociocultural possui. Com efeito, a racionalização do mundo da vida é resultado de um processo de aprendizagem e significa, além disso, um novo nível de aprendizagem - este novo nível consiste na fundamentação universalista, pós-tradicional, que se reflete tanto na estruturação das instituições e das práticas sociais quanto nos processos de socialização e de subjetivação que acontecem no seio dessas mesmas sociedades (cf. Habermas, 2012a, pp.296-299, e p.521; 2012b, p.540; 2003a, p.20).

A racionalização das imagens de mundo, própria das sociedades modernas, calcada na pretensão de universalidade das normas, instaura a racionalidade comunicativa como o viés a partir do qual a fundamentação pode ser afirmada - ou rejeitada - nesse seu aspecto universalista. Habermas utiliza o termo linguistificação do sagrado para significar exatamente este processo de modernização que transplanta a fundamentação outrora monopolizada pelas imagens de mundo míticas, religiosas e culturais para a discussão intersubjetiva cotidiana, a cargo dos indivíduos e dos grupos. Doravante, a validade das normas e das práticas não reside na autoridade inquestionada das tradições (elas que já tiveram sua autoridade esfacelada), mas em acordos intersubjetivos que alcançam universalidade e que são sempre passíveis de crítica. A autoridade das normas, nas sociedades modernas, racionalizadas, é dependente de procedimentos dialógicos que alcançam validade universal, posto que necessitam de razões formais, transcendentes aos contextos, alcançando, assim, a pretensão de universalidade, de imparcialidade que é necessária à objetividade dessas mesmas normas e práticas (cf. Habermas, 2012a, pp.587-588, p.683; 2012b, p.145, pp.195-196, p.525; 2003b, p.331; Honneth, 2003, pp.211-213). Ora, este nível pós-tradicional da consciência, ou seja, a possibilidade de se pensar, de se fundamentar e de se agir com base em procedimentos formais, universalistas de justificação, se torna realidade no desenvolvimento histórico da Europa, conforme nos diz Habermas: "o nível pós-tradicional da consciência moral se torna acessível em uma cultura, e mais precisamente na cultura europeia" (Habermas, 2012a, p.355; o grifo é de Habermas. Cf., ainda: 2012a, p.383).

A cultura europeia moderna, assim, possui certas estruturas formais e universalistas de consciência e de organização social que qualquer outra cultura, caso alcançasse certo grau de racionalização, também possuiria, o que significa que o universalismo moral (ou consciência moral pós-tradicional, descentrada) gestado a partir da modernidade europeia (e dela dinamizado para todo o mundo por meio de processos de colonização e, em alguns poucos casos, de processos de interação) possibilitaria a construção de um paradigma normativo que, pelo seu 
grau de generalidade, de formalização, de universalização, coloca o procedimento comunicativo de validação das normas como a base de qualquer projeto éticopolítico, dentro e fora das sociedades modernas - e não apenas possibilitando o ponto de vista moral para as ciências sociais que, então, salvariam, afirmariam sua capacidade crítica. Diz Habermas:

A posição universalista não precisa negar o pluralismo (...), mas percebe que essa multiplicidade de formas de vida está restrita aos conteúdos culturais e afirma que toda cultura, se for o caso de alcançar certo grau de 'conscientização' ou de 'sublimação', teria de compartilhar certas qualidades formais da compreensão de mundo moderna. A assunção universalista refere-se, portanto, a algumas características estruturais e necessárias próprias a mundos da vida modernos (Habermas, 2012a, p.326; os grifos são de Habermas).

As culturas as mais diversas, se engrenassem em um caminho de desenvolvimento sociocultural análogo à racionalização das imagens de mundo própria à modernização ocidental, acabariam inevitavelmente por desenvolver elementos básicos constituintes de uma consciência moral universalista, pós-tradicional: secularização, individualização progressiva, institucionalização, direito positivo e ética formalista. Em suma, teriam de alcançar uma consciência moral universalista. Esta é a tão defendida relação interna entre modernidade e racionalidade de que fala Habermas e é aqui que a ideia de cultura esclarecida ou que possibilitaria autorreflexão e emancipação encontra seu sentido: modernidade tem a ver com a consolidação da autonomia individual e da justificação universalista concernente às normas, às práticas e às instituições sociais, que, em uma época de secularismo, já não são dinamizadas a partir das concepções metafísico-teológicas ou míticas de mundo (cf. Habermas, 2002a, p.08; 2003a, p.25; Honneth, 2007a, pp.102-115; Catroga, 2006, pp.15-34). As sociedades modernas teriam um futuro (cf. Habermas, 2002a, p.09); nelas, o projetar do futuro, a partir da tematização e da formulação do presente, encontra seu sentido em uma história totalmente por fazer, que se baseia no fato de que, aqui, a racionalização do mundo rompeu tanto com a autoridade quanto com uma organização social, cultural e mesmo natural já prontas e totalizantes, às quais os indivíduos necessitariam apenas aclimatar-se. 0 que não é o caso das sociedades tradicionais.

\section{O racionalismo ocidental como ponto cego da teoria da modernidade de Habermas}

Realizei esta reconstrução do lugar e do entendimento que Habermas confere ao racionalismo ocidental em sua teoria do agir comunicativo porque é a partir dele que o referido pensador constrói sua teoria social crítica que conjuga fundamentação filosófica e diagnósticos sociológicos do presente. 0 racionalismo ocidental the 
permite, entre outras coisas: sustentar sua defesa de uma razão cética, mas não derrotista; defender a necessidade de radicalização do projeto iluminista; defender a segunda chance da Europa concernente à condução de um projeto ético-político de integração mundial diante da consolidação da globalização econômica e de seus desastres, e tendo em conta a desmoralização norte-americana após as guerras do Afeganistão e do Iraque, levadas a efeito na administração Bush; fundamentar e sustentar uma posição moral universalista em uma época de pluralismo e de pensamento pós-metafísico. Também lhe permite, como acredita, apropriar-se das críticas à razão, feitas em termos de Escola de Frankfurt (Adorno, Horkheimer e Marcuse) e mesmo daqueles que ele chama de pós-estruturalistas (Foucault, Derrida, etc. ), mas sem negar o racionalismo ocidental como um todo. Ou seja, o racionalismo ocidental é fundamental, no projeto filosófico-sociológico habermasiano de crítica e de afirmação da retomada da modernidade. Sem ele, Habermas perde sua base teórico-prática.

Minha crítica a Habermas, nesta seção e a partir disso, consiste em que ele tem de pagar um preço extremamente alto para, conforme sua intenção, salvar um projeto crítico de filosofia e de sociologia calcado na afirmação da modernidade ocidental. Esse preço consiste, por um lado, em uma idealização intolerável desse racionalismo ocidental que acabei de reconstruir na primeira parte do texto, um racionalismo grandemente cego e pretensioso em relação aos seus fundamentos e ao seu potencial de universalidade, reforçando, direta e indiretamente, um sentido colonizador, missionário e messiânico dessa mesma cultura europeia, próprio do século XVIII e XIX (mas ainda latente no século XX em diante), quando do contato com as culturas ameríndias e africanas; e, por outro, na existência de um déficit histórico-sociológico que the permite defender um importante futuro ao racionalismo ocidental devido ao fato de, ao idealizá-lo, desvincular grandemente esse mesmo racionalismo ocidental do próprio desenvolvimento da cultura, da economia, da política e das instituições modernas tanto dentro das sociedades europeias modernas quanto nos processos colonizatórios, missionários e messiânicos impostos por elas a outras culturas e povos. Somente essa desvinculação (ou a existência de um mínimo de desvinculação) histórico-sociológica de um ideal de racionalismo ocidental em relação às práticas dinamizadas desde as sociedades europeias modernas pode dar um mínimo de sustentáculo a uma radicalização do projeto racionalista, de que fala Habermas. Mas essa desvinculação, como acredito, torna cega e pretensiosa tal defesa do racionalismo, assim como reforça sua superioridade, base dos projetos colonizatórios, missionários e messiânicos dinamizados desde as sociedades europeias modernas para todo o globo - e vigentes hoje sob a forma de uma modernização econômica e cultural incontroláveis e avessas a outras formas de produção da vida material e práticas e simbolismos de mundo, intervenções militares com sentido 
humanitário, condenações morais e solapamento da integridade cultural de concepções de mundo e de povos considerados primitivos ou bárbaros em seus valores e práticas, quando comparados com o pretenso caráter progressista, civilizador e humanizador desse mesmo racionalismo ocidental em sua pretensão de possibilitar um modelo universalista de fundamentação e, com isso, de cultura, de homem, etc.

Primeiramente, o racionalismo ocidental não assume todas as consequências epistemológico-morais e mesmo políticas da irredutibilidade de cada concepção cultural em relação às outras. A base do pensamento pós-metafísico de que fala Habermas é o esfacelamento das concepções metafísico-teológicas de mundo, por causa da relativa consolidação, nas sociedades ocidentais, do pluralismo religiosocultural e do individualismo dos estilos de vida, correlatamente à hegemonia da ciência de pesquisa empírica. No que tange ao campo ético-político, o pluralismo religioso-cultural aponta para a contextualização dos valores, que dizem sempre respeito a um contexto específico, encontrando sentido apenas por causa dele. As democracias ocidentais, ao fundarem suas instituições, suas práticas e seus valores socialmente vinculantes, apelaram para um procedimentalismo de matiz jurídicoconstitucional que afirmava direitos e liberdades básicos enquanto direitos naturais (posteriormente direitos humanos), que possuímos pelo simples fato de nascermos humanos, como forma de se tentar superar a afirmação universalista de uma concepção de mundo em relação às outras, ou como forma de se evitar minimamente um projeto ético, político e cultural homogeneizador calcado na pressuposição da superioridade de uma concepção de mundo frente às outras (cf. Hunt, 2009, p.20). Junto a isso, um consenso eminentemente político sobre nossos valores sociais básicos daria o tom de uma cultura democrática marcada pela secularização e pelo laicismo, na qual, entretanto, os indivíduos e os grupos não abandonariam suas crenças religiosas e etnocêntricas mais básicas (ainda que as limitem, em alguns casos) (cf. Rawls, 2000, p.11; 2002, p.50, pp.56-57, p.181, p.244; 2003, §5, p.17, e §8, p.31).

Ora, a fundamentação epistemológico-moral, nessa época de pluralismo escancarado, se depara com o fato da irredutibilidade das concepções morais, culturais e religiosas umas em relação às outras. São visões de mundo que simplesmente não têm qualquer base comum de compreensão, de tradução e, em última instância, de entendimento recíproco (cf. Danner, 2014, pp.70-98; Bhabha, 1998, pp.23-26). Essa possibilidade de conciliação ou de aglutinação sob um mesmo guarda-chuva normativo é precária ao extremo, mesmo em sociedades democráticas. Como signifiquei no parágrafo imediatamente anterior, nem nessas sociedades democráticas é possível a defesa de um único modelo normativo, epistemológico-moral, para as diferentes concepções de mundo. Os consensos políticos não raras vezes exigem mais do que a afirmação da anterioridade dos direitos humanos ou de direitos civis e políticos; exigem também a supremacia de certa visão de mundo específica em relação a 
outras. E o racionalismo, nesse quesito, serve como a base dessa concepção de mundo pretensamente superior, mormente quando, nas sociedades democráticas ocidentais, estão em jogo modos de vida modernos (racionalização, individualismo, produção material capitalista, instrumentalização da natureza, progresso técnico-científico, etc.) que, para serem afirmados, precisam minimizar a importância ou solapar os direitos à sobrevivência e às práticas e simbolismos das comunidades tradicionais (indígenas, quilombolas, etc.). Habermas está consciente dessa incomensurabilidade das concepções de mundo entre si - inclusive está consciente de que nem a filosofia e nem a ciência podem dar a última palavra quando se trata da fundamentação das normas e das práticas. Sua proposta de que o procedimento de formalização ou de universalização das normas apresenta apenas um método para a validação delas, não o seu conteúdo, que é sempre dado pelas discussões práticas entre os diferentes participantes, em pé de igualdade uns em relação aos outros, tenta evitar a imposição prévia dos conteúdos práticos (cf. Habermas, 2004, p.67).

Porém, o próprio método de universalização das normas já apresenta, ainda que indiretamente, o caminho e, mais ainda, um modo de vida a ser alcançado coletivamente, que é aquele pressuposto em termos de racionalismo ocidental: ou seja, pressupõe que somente as normas universais podem ter validade prática, colocando a racionalização como o cerne da legitimação teórico-prática. Como disse, se já em termos democráticos isso é difícil (porque afirmamos sempre a episteme racionalista, principalmente frente às comunidades tradicionais marginalizadas e relegadas à periferia da democracia - novamente lembraria dos indígenas e dos quilombolas), quando miramos o âmbito internacional nos deparamos, então, com problemas práticos muito mais graves (a episteme racionalista serviria como substrato para as propostas de fundamentação? O racionalismo ocidental seria o modelo formalista capaz de garantir tanto o método quanto o conteúdo dos processos de fundamentação, principalmente em relação aos fundamentalistas? Fundamentalistas segundo os racionalistas, segundo os modernos? 0 racionalismo leva diretamente à democracia e aos direitos humanos?). Esses problemas somente seriam evitados (e, então, o racionalismo somente se safaria ileso) se ignorássemos a história dos processos colonizatórios levados a efeito desde a Europa e também se fôssemos cegos sociologicamente falando em termos da realpolitik hodierna da globalização. Mas, conforme penso, não precisamos e não podemos ser cegos nem histórica nem sociologicamente, a fim de dar razão à proposta de fundamentação de Habermas. Ele mesmo se serve de mudanças históricas que considera importantes para mostrar a incapacidade de teorias sociológicas ou filosóficas rivais de diagnosticarem ou fundamentarem consistentemente fenômenos contemporâneos. Nesse sentido, seguindo sua própria tendência, poderíamos apontar para o fato de que o universalismo moral, em uma época de pensamento pós-metafísico, é um contrassenso, porque 
pressupõe a afirmação da superioridade do racionalismo ocidental frente às outras concepções de mundo - tanto dentro do Ocidente quanto fora dele. Pressupõe, ainda, a possibilidade de que países e instituições políticas supranacionais o assumam como bandeira para a intervenção, o que, levando em conta a história dos processos de colonização e análises sociológicas da realpolitik hodierna, não pode ser feito de maneira inocente.

Ora, a consequência mais clara do pensamento pós-metafísico, que no caso de Habermas não é levada a sério, é o próprio ocaso da fundamentação universalista e, assim, da própria pretensão de o racionalismo ocidental oferecer a plataforma para tal intento cosmopolita. Nossa época, conforme penso, pôs por terra as fundamentações universalistas, fortes ou fracas. A irredutibilidade das concepções de mundo entre si, sua intraduzibilidade recíproca, não apenas impede a afirmação de um conjunto específico de conteúdos práticos que teriam validade universal e que, assim, abstraindo dos contextos específicos, serviriam para a regulação das práticas de todas elas; essa mesma irredutibilidade das concepções de mundo entre si impede a própria crença de que um método formalista de fundamentação e de validação das normas poderia oferecer a solução para um mundo em que o pluralismo se consolidou de vez. 0 próprio método já dá a tônica e o sentido de que tipo de caminho deve ser partilhado. Como pôde ser percebido na primeira parte deste texto, não é apenas a afirmação de um procedimento universalista de discussão e de validação de normas que está por trás do racionalismo ocidental, e sim a pressuposição, direta ou indireta, de um modo de vida racionalista que é próprio de tradições culturais surgidas desde a Europa e que são afirmadas como a medula espiritual desse mesmo Ocidente construído desde a Europa com um sentido claramente ufanista, calcado na ideia de cultura e de humanismo superiores em relação ao resto (inclusive colocando as imagens míticas de mundo daqui em um passado distante e ainda ingênuo, sendo que sua superação representaria um momento de maturação dessa mesma cultura europeia, frente a si mesma e frente às outras culturas). É importante percebermos que essas tradições andam de mãos dadas com a proposta de um método formalista, na medida em que é seu conteúdo que subjaz às justificações de modelos e de práticas institucionais que se escoram no universalismo moral quando se trata de analisar, de realizar intervenções e de efetivar propostas políticas de alcance global. Por outras palavras: não há um método de universalização das normas que seja puro em relação aos conteúdos do contexto em que ele surgiu. E minha reconstrução dos fundamentos do racionalismo ocidental na teoria da modernidade de Habermas está aí para provar que a afirmação colonizatória, messiânica e missionária de uma forma de vida que é europeia subjaz explicitamente a tal método universalista - no caso, ao projeto da modernidade e sua proposta calcada no racionalismo. Mas isso viola a integridade e a autorrefencialidade dos contextos particulares de uso, referidos 
sempre a si mesmos em primeiro lugar e detentores de uma lógica evolutiva e simbólica própria. A ideia de irredutibilidade do outro, que o racionalismo ocidental tanto prega, não pode significar, na época do pensamento pós-metafísico, um projeto de integração ético-político universalista sem metafísica, mas sim a própria recusa desse projeto ético-político universalista, tanto por causa da impossibilidade de se abstrair método de universalização e conteúdo cultural europeu moderno quanto por causa da vinculação histórico-sociológica desse conteúdo com instituições, práticas e fundamentações colonizatórias, missionárias e messiânicas veiculadas desde o contexto euronorcêntrico para todo o globo, visto sempre em um papel de periferia, enquanto aquele teria uma função de ponta-de-lança na proposição e na condução de qualquer projeto universalista integrativo e emancipatório. Doravante, esse mesmo racionalismo precisa - ele que se afirma como possibilitando autorreflexividade retornar para dentro de suas fronteiras.

Em segundo lugar, e como consequência do ponto anterior, temos a idealização romântica desse mesmo racionalismo ocidental, por causa de sua capacidade de formalização e de descentração no que tange à fundamentação das práticas e dos valores. Com efeito, há uma ideia romântica por trás do racionalismo europeu, ocidental, em seu projeto emancipatório de cunho ético-político universalista: quando menos etnocentrismo, mais pluralismo e individualismo. Quanto mais pluralismo e individualismo, mais justiça, liberdade, igualdade. Por outras palavras, quanto mais capacidade de se abstrair dos contextos e de se alcançar um nível moral pósconvencional, mais capacidade de se resolver os problemas intersubjetivos, porque se põe por terra as tradições arcaicas, ossificadas e acríticas (e que baseiam sua evolução exatamente nessa capacidade acrítica de adaptação individual e grupal ao ambiente social e natural exterior - percebido como exterior). Habermas é explícito nesse ponto:

Quando maior for a complexidade da sociedade e quanto mais se ampliar a perspectiva restringida etnocentricamente, tanto maior será a pluralização de formas de vida e a individualização de formas de vida, as quais inibem as zonas de sobreposição ou de convergência de convicções que se encontram na base do mundo da vida; e, na medida de seu desencantamento, decompõem-se os complexos de convicções sacralizadas em aspectos de validade diferenciados, formando os conteúdos mais ou menos tematizáveis de uma tradição diluída comunicativamente (Habermas, 2003a, p.44).

A visão romântica da modernização, portanto, acredita que o universalismo epistemológico-moral (ou, por outras palavras, as estruturas de consciência racionalistas, formalistas próprias da modernidade europeia) permite uma visão crítico-emancipatória de mundo porque, primeiro, dissocia natureza, sociedade e individualidade, garantindo, em segundo lugar, a assunção da subjetividade reflexiva e a afirmação da cultura e da sociedade como algo instrumental, profano, passível de 
domínio, de revisão crítica e de transformação. Não por acaso, a subjetividade reflexiva, a instrumentalização da natureza e a historicização da sociedade (em particular os dois primeiros) são a base do projeto modernizador capitalista encampado desde a Europa. A subjetividade reflexiva e a instrumentalização da natureza (res cogitans versus res extensa) permitem, no primeiro caso, a desvinculação teórico-política, própria do liberalismo moderno, entre uma compreensão de subjetividade formalista e os efeitos macroestruturais das instituições em relação aos processos de socialização e de subjetivação, e, no segundo caso, a afirmação do trabalho sobre o homem e, principalmente, sobre a natureza como a base do desenvolvimento sociocultural (o homem se desenvolve enfrentando a natureza). Como consequência do primeiro caso, a subjetividade é percebida como ontologicamente anterior e independente ao social e, como consequência do segundo caso, a natureza é pura materialidade, sem qualquer resquício substantivo de normatividade. A subjetividade reflexiva, como base ontológica do social, leva seja à concepção de política negativa no âmbito das instituições públicas, seja à consolidação de uma posição de superioridade dessa posição moderna e liberal calcada na subjetividade reflexiva frente às posições de mundo míticas, o que fundamenta a imposição de conteúdos daquela em relação a estas, sob o argumento retórico de que deve-se proteger a subjetividade reflexiva ou de que esta precisa ser educada de acordo com um padrão civilizacional e humanista modernos. A concepção de natureza enquanto res extensa, própria da modernidade europeia, encampa uma atuação material em grande medida insensível e predatória em relação ao meio ambiente, não apenas por retirar dele qualquer resquício de normatividade, mas também e principalmente por tê-la separado da sociedade e da individualidade - inclusive entendendo-a como antagônica à sociedade e à subjetividade reflexiva.

Ou seja, uma modernização romântica, ao atribuir centralidade ao universalismo moral e à racionalização do mundo, foi a responsável pela destruição das culturas arcaicas por parte da cultura europeia moderna nos processos de colonização implantados desde a Europa, simplesmente porque, calcada nos seus ideais de subjetividade reflexiva, de sociedade enquanto estrutura profana e de natureza como res extensa, solapou todas as visões de mundo míticas que, conforme se pôde perceber na primeira parte deste texto, se fundam nesta imbricação profunda e mágica entre natureza, sociedade e individualidade. Não há, portanto, maior reflexividade no racionalismo moderno em sua pretensão de fundamentação universalista das normas, em sua consciência moral pós-convencional; há, isto sim, um processo explícito e implícito de contínua negação do não moderno, do arcaico, do primitivo, que precisa dialogar ou se aclimatar a uma modernização que é acrítica porque incapaz não apenas de autocrítica sincera, mas de parar, de cessar em termos de desenvolvimento rumo ao universalismo. A modernização 
em seu projeto universalista é como o processo de autovalorização do capital por meio da exploração do trabalho: precisa progredir sempre, não obstante as crises cíclicas de acumulação ou, comparativamente, não obstante as barbáries praticadas em nome da modernização - as barbáries, de um modo geral, seriam percebidas não como o elemento mais importante dessa mesma modernização ou como sua causa direta, mas como um acidente de percurso, facilmente corrigível desde dentro da modernização. A modernização, conforme penso, é totalizante e nada pode escapar à sua pretensão universalista, sob pena de ela não completar-se como universalização, como racionalização. Com isso, as imagens de mundo míticas, em um universo dominado pela modernização hegemônica, são relegadas à periferia e paulatinamente destruídas, como momentos de um passado infantil da humanidade.

Em terceiro lugar e como englobando os dois pontos anteriores, temos a cegueira histórico-sociológica do papel efetivamente desempenhado pelo racionalismo em termos de destruição das comunidades arcaicas tanto dentro da Europa quanto a partir das sociedades europeias modernas em seus processos colonizatórios. Essa cegueira histórico-sociológica apresentada por Habermas somente é possível porque ele dissocia, em grande medida, uma versão idealizada desse mesmo racionalismo, caracterizada pela assunção da consciência epistemológico-moral universalista e da subjetividade reflexiva, em relação, primeiro, à Europa e, segundo, às instituições, às fundamentações e às práticas que, na Europa e depois a partir dela frente a todos os povos alcançados pelo seu processo de colonização social, econômico e cultural, foram destruídos ou marginalizados por meio da afirmação da modernização, do ideal de civilização, de homem e de valores que as sociedades europeias encamparam como base dessa mesma colonização. Considero tal separação entre normatividade e facticidade um erro crasso de uma teoria social crítica e uma tarefa forçada de idealização do racionalismo ocidental como condição dessa mesma empreitada crítica. Como é possível separar a pretensão de universalidade do racionalismo ocidental, por um lado, e as práticas e fundamentações que, direta ou indiretamente em nome dele, estiveram na base de legitimação dos processos colonizatórios, missionários e messiânicos levados a efeito pelas potências europeias? Como separar esse duplo campo hoje, em que uma visão ético-política de cunho euronorcêntrico calcada no universalismo da modernização, julga e age internacionalmente com base em direitos humanos ou na democracia e nas liberdades individuais? Como ignorar o ufanismo da visão secular da democracia como superior aos (assim chamados desde o Ocidente) fundamentalistas ou primitivos? Conforme penso, não apenas não é possível tal separação entre normatividade e facticidade concernente ao racionalismo ocidental em sua pretensão de universalidade, senão que, uma vez imbricados os dois âmbitos, como eles efetivamente devem ser, resulta-nos injustificada a pretensão universalista irradiada pelo racionalismo ocidental, injustificada porque colonizatória, messiânica 
e missionária. Essa cegueira histórico-sociológica, essa relativa desvinculação entre uma visão ideal do racionalismo ocidental e as práticas nefastas levadas a efeito pelas potências europeias nas suas atividades colonizatórias, incrivelmente, permite a Habermas defender uma segunda chance da Europa concernente à condução de um projeto emancipatório em nível mundial. Ele diz:

O racionalismo ocidental precisa cair em si mesmo e superar suas próprias cegueiras, a fim de poder abrir-se dialogicamente para aquilo que pode apreender das tradições das outras culturas. Um encontro intelectual digno desse nome teria a capacidade de trazer à tona elementos da nossa própria tradição que foram soterrados. A Europa precisa servir-se de um de seus pontos fortes, a saber, o seu potencial de autocrítica, sua força de autotransformação, a fim de relativizar-se mais radicalmente a si mesma em contato com o outro, com o estranho. E isso é o contrário do eurocentrismo. Esse somente poderá ser vencido por nós através daquilo que o espírito da Europa tem de melhor (Habermas, 1993, p.94; o grifo é meu).

Note-se a ideia de "um encontro intelectual" do racionalismo com as tradições culturais arcaicas ou fundamentalistas como um momento de aprendizado para esse mesmo racionalismo. É interessante que, aqui, é necessário um momento intelectual como condição do diálogo e do aprendizado. Ou seja, é necessário um procedimento de racionalização entre modernização e culturas arcaicas que leva ao diálogo e ao aprendizado. 0 que quero significar com isso está em que a modernização não apenas pressupõe direta ou indiretamente a superioridade do racionalismo e do universalismo como base de sua evolução, senão que sequer consegue abandonálo quando se trata de achegar-se às culturas arcaicas. A modernização é incapaz, portanto, de autocrítica, contrariamente ao que pensa Habermas, porque não apenas é incapaz de colocar-se no lugar do outro oprimido ou periférico, mas porque também sempre reafirma a necessidade de racionalização (encontro intelectual, diálogo, aprendizado) como o médium do encontro. Ela não consegue aprender por meio do silêncio epistemológico-moral, por meio do que, por ser indizível, intraduzível, não-racionalizável, exige a cessão completa da postura epistemológico-moral universalista, dissecatória e avaliativa (com base em padrões racionais), própria dessa mesma modernização.

Em quarto lugar e como consequência do momento anterior, temos a crença ingênua e ainda romanticizada de que somente mais racionalismo crítico e, assim, mais modernização podem superar as deficiências do próprio racionalismo, da própria modernidade. Isso se deve à pressuposição de uma profunda e efetiva característica autorreflexiva enquanto própria do racionalismo ocidental e da modernização em sua pretensão universalista. Os fundamentos dessa reflexividade, que já foram apresentados no primeiro ponto desse texto, permitem que a modernização - tanto em seu viés institucional (Estado, mercado, direito) quanto em seu viés sociocultural (democracia, direitos, secularização), bem como em seu viés epistêmico (a 
pretensão de universalidade própria à ciência e à moral fundamentadas desde o racionalismo ocidental) - esteja consciente não apenas de seus pontos positivos, do quanto ela representa um progresso na história do gênero humano (que ela mesma reconstrói de maneira unitária), mas também de suas patologias, de seus efeitos destruidores dentro de si mesma e fora de si mesma. Ora, é essa autoconsciência que lhe permite estabilizar-se e corrigir-se, de modo a manter-se sempre em expansão, em desenvolvimento, representando, ainda conforme essa mesma autoconsciência moderna, o baluarte para um projeto cosmopolita de integração e o fundamento da pretensão epistemológico-moral universalista. Aliás, a pretensão universalista e a autorreflexividade são dois momentos interligados, interdependentes desse mesmo racionalismo. É essa base correlatamente universalista e autorreflexiva da modernidade que, segundo Habermas, não é desestruturada com os efeitos destruidores e com as patologias dessa mesma modernidade. Ele diz:

Somente um esclarecimento maior - docta spes - é páreo para as devastações do Iluminismo. Para mim, uma crítica total da razão, que confunde a própria razão, não vale grande coisa. (...) com isso, eu não quero endeusar a razão, e sim, ao contrário, dizer que nós só podemos ter clareza sobre os limites de nossa razão se agirmos de modo racional. Não podemos lançar fora a modernidade, que é determinada por esta figura básica do pensamento kantiano, como se ela fosse uma camisa suja. As condições de vida modernas, que nós não escolhemos por nós mesmos, e sob as quais nos encontramos, são inevitáveis do ponto de vista existencial; mesmo assim, aos olhos despertos da modernidade, elas significam um desafio a mais, não uma simples fatalidade (Habermas, 1993, p.92; os grifos são de Habermas).

A figura básica do pensamento kantiano de que fala Habermas consiste na correlação entre universalidade e crítica, entre fundamentação universalista e autorreflexividade. E essa seria, como se torna básico na tradição filosófica moderna, a essência do racionalismo ocidental. Como consequência, quanto mais universalidade, mais crítica; quanto mais crítica, mais a modernização pode seguir avançando no rumo certo, evitando as devastações internas e externas à modernidade, até tornarse um projeto global, não apenas em termos de universalização das instituições gestadas na modernidade europeia e hoje em processo de gradativa consolidação global (como é o caso do mercado), mas também dos fundamentos epistemológicomorais do racionalismo ocidental. Por outras palavras, o universalismo moral moderno, gestado desde a Europa, oferece os lineamentos normativos gerais ou um guarda-chuva normativo que, em seu intento cosmopolita, permite a proteção e o fomento das culturas e das tradições particulares, dado o formalismo daquele. Mas também há um fundamento escondido nesse mesmo racionalismo ocidental que é a condição de sobrevivência desse mesmo racionalismo, a saber: sua pretensão à universalidade, seu movimento rumo à universalidade. Esta é a orientação básica do racionalismo, sem a qual ele não pode sobreviver como racionalismo, isto é, 
como proposta de um guarda-chuva normativo que serviria, por causa de seu grau de formalização, como ponto de vista moral capaz de gerar a autorreflexividade necessária às instituições e às práticas socioculturais de qualquer contexto. Com efeito, aqui, a pretensão universalista somente se sustenta e se afirma se conseguir provar tanto a parcialidade das visões de mundo presas ao contexto e incapazes de formalização e de individuação (supostamente é o caso das visões míticas de mundo) quanto, por outro lado, a capacidade de esse mesmo universalismo alcançar tal patamar de formalização e de individuação gerador da crítica. Esse fundamento escondido, absolutamente interligado à universalidade e à crítica acima comentadas, é que, em um sentido, solidifica a confiança extrema de que o racionalismo oferece uma alternativa de integração moral e de ajuizamento epistemológico consistentes, bem como, em outro sentido, de que ele é uma visão de mundo superior em relação às visões míticas de mundo, o que torna menos aguda a violência da colonização institucional e, no caso do racionalismo, epistemológico-moral. Por isso, o discurso universalista é tão intrínseco à modernização quanto o é o desenvolvimento global do capitalismo (que é um sistema eminentemente moderno). São dois momentos, inclusive, imbricados e dependentes ao extremo, que impõe de maneira cooperativa o universalismo como a verdade e a maturação das posições contextuais, como forma de resolução de todos os problemas existentes, e o progresso material como realização da justiça e da satisfação social e individual para todos. Ou seja, um "sempre avante!" como o mote da superação dos problemas institucionais, das patologias socioculturais e das tradições deficitárias. Com isso, não obstante todos os déficits, mais modernização reflexiva pode salvar essa mesma modernização de uma derrocada. Ora, essa crença ingênua na auto-regeneração da modernidade é, direta ou indiretamente, uma apologia à pretensão universalista da modernidade, teórica e praticamente; uma legitimação do fato de que, mesmo diante de todos os problemas oriundos da modernização, ela pode ser aperfeiçoada de modo a continuar ininterruptamente seu caminho rumo ao cosmopolitismo, realizando essa vocação de guarda-chuva normativo dos contextos particulares, que ela desde longa data assume.

Em quinto lugar e como consequência do momento anterior, temos a errônea e presunçosa ideia de que o universalismo é o fundamento do sentido e da validade das posições particulares de cada contexto, na medida em que a validade dessas mesmas posições e práticas precisa ser plasmada em um sentido universal ou sustentar-se a partir do universal, se quiser garantir validade. Isso, quando se trata da proposta racionalista de um cosmopolitismo epistemológico-moral, torna-se agudo, porque as culturas incapazes de formalização (ainda de acordo com o racionalismo) são colocadas em segundo plano. Como consequência, a pretensão de se fundamentar objetivamente valores e práticas, com a ligação intrínseca entre objetividade e 
formalismo ou universalidade, alça o universalismo ao papel de verdade, de guia, de juiz do contextualismo, por assim dizer. Temos, aqui, uma afirmação apressada da episteme racionalista frente aos simbolismos e práticas das comunidades arcaicas, já que, neste modelo (como ficou visível a partir da reconstrução do ponto de partida da teoria da modernidade de Habermas), as possibilidades de integração e de legitimação das normas passam pelo procedimento de universalização - e de que este procedimento de universalização seria a chave para se conceber a dinâmica moderna de vida e de consciência. Mas não somente isso. Há também, direta ou indiretamente, a pressuposição das estruturas de consciência modernas que geram e sustentam a pretensão universalista do racionalismo, a saber, a formalização, a separação entre natureza, sociedade e individualidade. Contribui-se, assim, para que as visões míticas de mundo, julgadas a partir do universalismo e, consequentemente, da cultura moderna (euronorcêntrica), sejam solapadas em sua complexidade e diminuídas em seu valor interno, vistas negativamente como infantis e acríticas tudo isso desde fora, desde a visão moderna, hoje euronorcêntrica, de mundo, de cultura, de saber.

\section{Considerações finais}

Não a radicalização do racionalismo ocidental, mas a radicalização das vozes das culturas arcaicas (assumindo essa denominação utilizada por Habermas) poderia possibilitar o projeto crítico, principalmente quando se percebe que a intersecção entre natureza, sociedade e individualidade evita uma postura predatória tanto do ambiente natural quanto da vida social e individual. Não a retomada do projeto racionalista, mas sua supressão enquanto projeto racionalista, poderia garantir o refreamento, em primeira mão, da modernização, que, como penso, é a grande vilã. Por fim, isso significaria que o máximo que o racionalismo ocidental pode fazer é voltar-se contra si mesmo, no sentido de uma crítica e de um refreamento internos, baseados na percepção não apenas de seus próprios déficits, mas também da irredutibilidade das outras concepções de mundo, das outras culturas, que impedem esse ideal universalista dinamizado desde o racionalismo europeu. A modernidade somente pode ser salva de uma bancarrota total se voltar-se a uma crítica interna à sua visão colonizadora calcada no racionalismo e em seu projeto de universalismo epistemológico-moral, bem como, consequentemente, se atacar a globalização econômica capitalista hoje em voga e a utilização ideológica dos fundamentos da democracia liberal como forma não apenas taxonômica no que se refere à avaliação moral das diferentes sociedades (decentes, foras da lei, fundamentalistas, etc.), mas também como justificação das intervenções e das práticas civilizacionais que instituições construídas desde a Europa e com suposto alcance universal utilizam em 
sua postura imperialista, colonialista, genocida. Por outras palavras, o racionalismo precisa ser parado no seu intento universalista, a partir, em primeiro lugar, de uma autocrítica interna. A modernização descontrolada, com sua aspiração incessante e irrefreável à totalização, isto é, à globalização, é o verdadeiro perigo a ser superado, internamente às sociedades ocidentais (na medida em que também aqui destrói as poucas comunidades tradicionais ainda restantes, com seus saberes e suas práticas, e a própria a natureza, consolidando situações de exploração e de pobreza material que contradizem o discurso progressista e ufanista em torno à modernidade - como se pode perceber na atual crise socioeconômica). E a modernização é um perigo a ser superado também nas relações internacionais, na medida em que, como venho dizendo, ela é o mote para a globalização econômica e cultural, na medida em que o universalismo é a base teórico-normativa das intervenções colonizadoras e imperialistas.

A autocrítica da modernidade não significa a continuação do projeto de modernização em uma perspectiva global, nem a continuação infundada de afirmação do arcabouço epistemológico-moral próprio do racionalismo enquanto base desse projeto cosmopolita. A autocrítica da modernidade significa, neste contexto, a supressão da modernização em seu duplo aspecto: a expansão incontrolada da integração econômica mundial desigual, acompanhada da universalização das práticas políticas que the dão sustentação, mormente a democracia liberal; e a crença intelectual-cultural, gestada na - e propalada pela - Europa aos quatro cantos (por livros, filmes, sistema de ensino, regime político, filosofia acadêmica de matiz euronorcêntrico, etc.), da superioridade do procedimentalismo universalista no que tange à fundamentação dos valores e das práticas, colocando-se, assim, o universalismo como a verdade, como o critério normativo para a avaliação e o julgamento crítico das visões de mundo contextuais e de suas práticas. 0 refreamento desse duplo movimento, que se autolegitima e se sustenta reciprocamente, pode impedir a continuação das catástrofes cotidianas, na medida em que, conforme argumento, os problemas que hoje vivemos, dentro das sociedades democráticas e, principalmente, em nível global, devem-se à modernização irrefreável e descontrolada, econômica e culturalmente, legitimada com base na pretensão universalista do racionalismo europeu, assumido acrítica e apressadamente (ou mesmo ideologicamente, no sentido marxiano) como superior às outras formas de vida e concepções de mundo. Estas catástrofes, portanto, são, em primeira mão, fruto direto da modernização econômica capitalista e da modernização culturalracionalista veiculadas, hoje, desde o horizonte euronorcêntrico para todos os outros, tornando-se o padrão homogeneizador, unificador e civilizador básico que, como um rolo compressor, arrasa todas as posições (políticas, culturais, econômicas) alternativas que se opõem a ela. As alternativas à modernização são inimigas dessa 
mesma modernização simplesmente por serem alternativas, motivo pelo qual precisam ser assimiladas e paulatinamente destruídas. Ou seja, a modernização entrou em uma espiral destrutiva que, calcada nessa irrefreável necessidade de universalização como condição para sua (da modernidade) afirmação, põem em perigo a estabilidade de países, de culturas e de povos, tornando periféricos e aos poucos destruindo práticas, saberes e simbolismos alternativos, arcaicos. Ela perdeu, com isso, a pouca legitimidade que já tinha para seu intento universalista. Precisa ser parada.

\section{Referências:}

Bhabha, H. K. (1998). O Local da Cultura. Tradução de Myriam Ávila, Eliana Lourenço de Lima Reis e Gláucia Renate Gonçalves. Belo Horizonte: Editora da UFMG.

Catroga, F. (2006). Entre Deuses e Césares: Secularização, Laicidade e Religião Civil - Uma Perspectiva Histórica. Coimbra: Edições Almedina.

Danner, L. F. (2014). Um Fundamento para o Ecumenismo: a Irredutibilidade do Outro. Horizonte, Belo Horizonte, 12(33), pp.70-98.

Dubiel, H. (1993). Que es el Neoconservadurismo? Introducción y Traducción de Agapio Maestre. Barcelona: Editorial Anthropos.

Forst, R. (2010). Contextos da Justiça: Filosofia Política para além de Liberalismo e Comunitarismo. Tradução de Denilson Luís Werle. São Paulo: Boitempo.

Habermas, J. (1990). Pensamento Pós-Metafísico: Estudos Filosóficos. Tradução de Flávio Beno Siebeneichler. Rio de Janeiro: Tempo Brasileiro.

. (1991). La Necesidad de Revisión de la Izquierda. Traducción de Manuel Jiménez Redondo. Madrid: Editorial Tecnos.

(1993). Passado como Futuro. Tradução de Flávio Beno Siebeneichler. Rio de Janeiro: Tempo Brasileiro.

Barcelona: Ediciones Península.

(1997). Ensayos Políticos. Traducción de Ramón Garcia Cotarelo. - (2001). "El Criticismo Neoconservador de la Cultura en los Estados Unidos y en Alemania Occidental: Un Movimiento Cultural en Dos Culturas Políticas”. In: Giddens, A et al. Habermas y la Modernidad. Traducción de Francisco Rodríguez Martins. Madrid: Ediciones Cátedra.

- (2002a). O Discurso Filosófico da Modernidade: Doze Lições. Tradução de Luiz Sérgio Repa e de Rodnei Nascimento. São Paulo: Martins Fontes.

- (2002b). A Inclusão do Outro: Estudos de Teoria Política. Tradução de George Sperber e de Paulo Astor Soethe. São Paulo: Loyola.

- (2003a). Direito e Democracia: entre Facticidade e Validade (Vol. I).

Tradução de Flávio Beno Siebeneichler. Rio de Janeiro: Tempo Brasileiro. 
. (2003b). Direito e Democracia: entre Facticidade e Validade (Vol. II).

Tradução de Flávio Beno Siebeneichler. Rio de Janeiro: Tempo Brasileiro.

- (2004). A Ética da Discussão e a Questão da Verdade. Tradução de Marcelo Brandão Cipolla. São Paulo: Martins Fontes.

- (2012a). Teoria do Agir Comunicativo: Racionalidade da Ação e Racionalização Social (Vol. I). Tradução de Paulo Astor Soethe. Revisão Técnica de Flávio Beno Siebeneichler. São Paulo: Martins Fontes.

- (2012b). Teoria do Agir Comunicativo: sobre a Crítica da Razão Funcionalista (Vol. II). Tradução de Flávio Beno Siebeneichler. São Paulo: Martins Fontes.

Honneth, A. (2003). Luta por Reconhecimento: a Gramática Moral dos Conflitos Sociais. Tradução de Luiz Repa. São Paulo: Editora 34.

- (2007a). Sofrimento de Indeterminação: Uma Reatualização da

"Filosofia do Direito" de Hegel. Tradução de Rúrion Soares Melo. São Paulo: Editora Esfera Pública. - (2007b). Reificación: Un Estudio en la Teoría del Reconocimiento. Traducción de Graciela Calderón. Buenos Aires: Katz.

Hunt, L. (2009). A Invenção dos Direitos Humanos: Uma História. Tradução de Rosaura Echenberg. São Paulo: Companhia das Letras.

Rawls, J. (2000) Justiça e Democracia. Tradução de Irene Paternot. São Paulo: Martins Fontes.

. (2002). O Liberalismo Político. Tradução de Dinah de Abreu Azevedo. Brasília: Instituto Teotônio Vilela; São Paulo: Editora Ática.

- (2003). Justiça como Equidade: Uma Reformulação. Tradução de Cláudia Berliner. São Paulo: Martins Fontes. 